\title{
Central interference in error processing
}

\author{
ELDAD YITZHAK HOCHMAN \\ University of Haifa, Haifa, Israel \\ and \\ NACHSHON MEIRAN \\ Ben-Gurion University of the Negev, Beer-Sheva, Israel
}

\begin{abstract}
This study dealt with capacity limitations in error processing. Participants classified digits into three arbitrary categories (initial response). Half were required to correct their errors if an error was detected (correction response), and half were required to produce a second response, regardless of the correctness of the initial response (approval response). Auditory interference was introduced before, during, or after the initial response. Interference stimuli were to be recalled later and were, thus, considered to involve central processes. Results for before showed that although correction responses were elongated, approval responses given after erroneous initial responses were shortened. For during, both correction and approval responses were elongated. On the basis of our findings, we argue that the error process is generated before the erroneous response is given and that it is a central process in terms of being subjected to capacity limitations in the presence of other central processes.
\end{abstract}

One productive way in which to explore the functional characteristics of the human information-processing system is to focus on the processing capacity of various parts of the system. Although the capacity of the earliest stages of processing is high, the capacity of some later stages, such as response selection, is much lower (see, e.g., Pashler, 1994; Pashler \& Johnston, 1998, cf. Navon \& Miller, 2002). The goal of this study was to improve our understanding of capacity limitations in the error-processing system.

This question has important implications. For example, driving a car seems to require constant processing of steering errors. At least in some situations, such as heavy traffic or narrow roads, rapid indication and correction of an error are essential to our survival. If the error-processing activity is capacity limited, any activity that constitutes a response selection, even one as simple as choosing between the wiper control stick and the indicator control stick, might cause a delay in the detection of an error, and such delays are potentially fatal.

Various studies have established the existence of a central system for processing errors. Rabbitt (1966a), in a pioneering experiment, showed that participants were able to indicate when they erred without any error feedback from the experimenter. Later studies revealed that detection of an error is possible even without feedback from the participant's own peripheral neural system (Angel, Garland, \& Fischler, 1971; Higgins \& Angel, 1970).

Correspondence should be sent to E. Y. Hochman, Department of Psychology and Institute of Information Processing and Decision Making, University of Haifa, Mount Carmel, Haifa 31905, Israel (e-mail: ehochman@study.haifa.ac.il).
These findings led to the conclusion that the error information originates from the same system that generated the error. Later psychophysiological studies showed that when a participant makes an error in a choice response time (RT) task, a component of the event-related potential (ERP), called error-related negativity (ERN), is observed (Falkenstein, Hohnsbein, Hoormann, \& Blanke, 1991; Gehring, Goss, Coles, \& Meyer, 1993). The ERN is a sharp negative deflection in the ERP, which is monitored when participants commit an error. The ERN peaks around 100-150 msec following EMG activity onset (approximately $50-80 \mathrm{msec}$ after the keypress response; Falkenstein et al., 1991; Gehring et al., 1993). Although it is not entirely clear whether the ERN is related to error detection or error correction, the mere fact that it originates almost simultaneously with response onset accords with the assumption regarding a central error-monitoring system that uses the same information as that used for response selection.

Although the existence of a central system for error monitoring has been well established, the exact way in which errors are processed for detection and subsequent correction is far from clear. ERN literature supplies several explanations for its behavioral significance, diverging in the nature and complexity of the process it manifests. Falkenstein et al. $(1990,1991)$ interpreted the ERN as reflecting error detection - that is, a mismatch of a rather simple process in which the actual response is compared with the required response. Vidal, Hasbroucq, Grapperon, and Bonnet (2000) suggested that the ERN signifies a more complex response evaluation process, such as a comparison of some kind that might lead to error detection, and that the detection process is reflected in a later ERP positive component, the Pe. These authors 
also suggested the possibility that the error detection comes first and leads to an emotional response, which by itself produces the ERN. Others have argued that the ERN indexes a conflict between competing processes during response selection - that is, it might appear even in cases of correct responses when two responses are selected (conflict hypothesis) - and serves an evaluative, rather than strategic, function (Carter, Botvinick, \& Cohen, 1999; Carter et al., 1998; Carter et al., 2000). Finally, it has been suggested that the ERN is implicated in the remediation of erroneous behavior and, in particular, the reflection of inhibitory processes (Bernstein, Scheffers, \& Coles, 1995; Falkenstein, Hoormann, \& Hohnsbein, 1999).

Our goal was to test whether error processing is central, in the sense of having limited resources. According to Jolicœur (1999b), central processes or mechanisms occur after perception, but before the initiation of motor commands. These processes can receive input from different sensory modalities and can guide cognitive and motor behavior. One criterion for central processes is capacity limitations, often operationalized as proneness to interference when simultaneous performance of another task is required. For example, Jolicœur (1998, 1999b) suggested that while central processes are under way, other operations that also require central processing must wait. Using this criterion, research has shown several processes to be central, including response selection (McCann \& Johnston, 1992; Pashler, 1994), short-term consolidation (Jolicœur \& Dell'Acqua, 1998), mental rotation (Ruthruff, Miller, \& Lachman, 1995), and retrieval from long-term memory (Carrier \& Pashler, 1995).

In contrast to central processes, operations that do not require central processing are presumably preformed in parallel. For example, in the psychological refractory period paradigm (cf. Vince, 1948; Welford, 1952; see Pashler \& Johnston, 1998, for a review), researchers observed interference in the second of two speeded tasks when they were presented in rapid succession. According to Pashler and Johnston, interference arose because of limitations in parallel response selection, and it was assumed that sensory and perceptual processes of the two tasks were performed in parallel.

However, there is a possibility that error processing does not suffer from dual-task constraints. Nieuwenhuis, Ridderinkhof, Blom, Band, and Kok (2001) recorded EEG and monitored eye movements during an antisaccade task. They reported the occurrence of the ERN in response to unperceived error trials. They concluded that the error detection process reflected by the ERN operated independently of conscious perception. Hence, the error process may be, at least partially, automatic and effortless. However, Hochman and Eviatar (2004) recently presented evidence for a division of resources between initial processing and its monitoring mechanisms, which grows with the demands of the task. Hence, error processing may be, at least in some aspects, resource demanding.

In the present study, we adopted a paradigm originally introduced by Rabbitt (1966a), in which participants re- spond to each stimulus twice-first, with an initial response, then with a second (correction) response. Two experiments were presented in which participants were requested to classify digits into three arbitrary categories by pressing one of three keys in each initial or correction response. After the initial response had been given, the participants made a second choice response. One half of the participants were requested to give the second (correction) response only if they detected an error and to refrain from giving a second response otherwise. This group was, therefore, required to detect the errors in the first response. The other group was a control group, in which participants were requested to produce the second response (approval responses) regardless of the correctness of the initial response. The nature of the approval response will be described shortly. Using this manipulation, we tried to make the demands for the second response in the two groups as equal as possible, except for the need among the correction group to estimate the correctness of their first response. Experiments 1 and 2 differed only in the task given to the approval (control) group. In Experiment 1, the participants in the approval group were instructed to produce a second response immediately after each initial response. This response involved pressing the key to the right or to the left (varied between blocks) of the key used in the initial response. Thus, this second response, like the correction responses, also required consideration of the nature of the first response and a change in keypress but did not involve estimating response correctness. However, one could argue that the selection of the second response in the approval group was less demanding, more expected, and hence associated with shorter latencies than was that in the correction group. Namely, the participants could produce a double-press response to the stimulus. Hence, in Experiment 2 , in the approval group, the participants were told that a second response was to be made only if an arrow appeared immediately after the production of the initial response (the arrow appeared on about one seventh of the trials in each block, which was the proportion of correction responses out of all responses in Experiment 1). The arrow could point either to the right (indicating the following initial-to-second-response mapping: index-middle, middle-ring, ring-index) or to the left (indicating the following initial-to-second-response mapping: ring-middle, middle-index, index-ring). Thus, the control group in Experiment 2 needed to consider both the nature of their first response and an unrelated event, taking place immediately after it (such as the error indication).

In a recent article, Rabbitt (2002) showed that error correction is not affected by the need to respond to a signal appearing about $150 \mathrm{msec}$ after the execution of the erroneous response. Rabbitt (2002) concluded that the processes resulting in correction of an error can be completed, before they are interrupted by a new signal, within $150 \mathrm{msec}$ or less. Hence, in the present experiment, we introduced interference at three targeted time points: between 150 and $50 \mathrm{msec}$ before the anticipated response, 
between $50 \mathrm{msec}$ before the anticipated response and $50 \mathrm{msec}$ after it, and between 50 and $150 \mathrm{msec}$ after the anticipated response.

Our experimental design allowed us to compare the effects of the interference between three groups of responses: corrections, approvals in which the initial response was wrong (wrong approvals), and approvals in which the initial response was correct (correct approvals). Since participants usually correct response errors even when they are not instructed to do so (Cooke \& Diggles, 1984; Rabbitt, 1966a, 1967), we assumed that error monitoring would be common to all three. However, errors would be detected in the first two groups only. This means that in all three groups, a second response was to be selected, whereas error processing would occur in the first two only.

In a study by Gehring and Fencsik (1999), participants performed a flanker task, responding with the left hand for one target and with the right hand for the other. EMG was used to measure the strength of the response made with each hand. The participants very frequently reversed errors, and the EMG results indicated clearly that when errors occurred, there was typically temporal overlap between the error and the error-correcting response. EEG data indicated that the ERN coincided with the period of response overlap on error trials. These results were in accordance with earlier findings showing that the larger the amplitude of the ERN, the weaker the force with which the incorrect response was executed (Gehring et al., 1993). Gehring et al. argued that the process manifested by the ERN is related to the operation of a mechanism of response inhibition that acts to suppress an incorrect response. Later works also have claimed that the ERN reflects an inhibitory process (Bernstein et al., 1995; Falkenstein et al., 1999). On the basis of these studies, we assumed that the detection of an error and its processing occurs immediately after selection of an erroneous response, slightly before its overt (keypress) execution. Hence, we expected that if the error process is indeed central, interference presented before the erroneous response would postpone the error process and, as a result, postpone the selection of the second response for both corrections and wrong approvals, in which an error is detected, but not for correct approvals, in which no error is detected at that point in time. Since in all three response groups a second response was to be selected, we also expected that all three groups would be affected by interference presented around the execution of the initial response, where the interference would encounter the selection of the second response, which was common to all three response groups.

We also manipulated the cognitive load of the interference between participants. Three load conditions were tested. In the first interference condition, two tones out of four pairs of tones differing in pitch $(400+500 \mathrm{~Hz}$, $600+700 \mathrm{~Hz}, 800+900 \mathrm{~Hz}$, and $1000+1100 \mathrm{~Hz}$ ) were presented, one immediately after the other, for $50 \mathrm{msec}$ each, one to each ear. The participants were instructed to ignore the interference; hence, it was considered irrelevant.
In the second interference condition, one of the tone pairs was assigned to each block. One of the tones within a pair, randomly chosen, was presented on each trial for $100 \mathrm{msec}$. At the end of each trial, the participants were requested to decide, without time pressure, whether the tone was of high or low pitch. The third condition was identical to the first condition, except that at the end of the trial, the participants were requested to decide, without time pressure, whether the second tone in the pair was higher or lower than the first one. This last condition was the most demanding because it required memory for the tone sequence.

By manipulating load, we expected to reveal how demanding the error process is. In the first load condition, we expected the irrelevant interference stimulus not to interfere with the second response. The second and the third load conditions were, in essence, quite similar to the dual-task paradigm offered by Jolicœur and Dell'Acqua (1998), in which a visual display was presented first, followed by an auditory signal. A speeded response to the auditory signal was required, whereas the information in the visual display was to be recalled later (in some of their experiments, the stimuli to be recalled later were presented after the stimuli to be responded to immediately; see Jolicœur, 1999a). Their results showed that RTs to the auditory signal were elevated. Jolicœur and Dell'Acqua interpreted the results as evidence that encoding information into short-term memory (STM) involves a distinct process, which they called short-term consolidation (STC). They suggested that STC has limited capacity and that it requires central processing mechanisms. Jolicœur and Dell'Acqua also showed that the greater the number of items to be consolidated into STM, the longer it takes to select the response to the stimuli in a speeded task. Thus, in the present study, we manipulated cognitive load by changing the number of items to be recalled later between participants. We assumed that if the error process was as demanding as response selection, both processes would be affected by the load condition, and the greater the number of items to be recalled, the longer it would take to produce the second response.

\section{EXPERIMENT 1}

\section{Method}

Participants. The participants were 60 undergraduate students who took part in the experiment as part of an introductory course requirement. Their mean age was 22 years. All of them reported being healthy and right-handed, having normal or corrected-to-normal vision, and having normal hearing.

Design. Half of the participants were assigned to the correction condition, and half to the approval condition. In each of the response type conditions (corrections and approvals), the participants were assigned equally among the three interference load conditions. Hence, in the present study, the response type condition and the interference load condition served as between-subjects variables, and interference timing served as a within-subjects variable.

Stimuli. The visual stimulus was a digit from 1 to 9 . The digits were presented in the center of the computer screen, within a focusing frame, and their size (in visual angle) was $0.5^{\circ}$. The focus- 
ing frame consisted of four horizontal lines, $1.7^{\circ}$ each. Two lines were presented above the digit, and two lines were presented beneath the digit $\left(0.57^{\circ}\right.$ and $0.69^{\circ}$ from the digit). The caption "you did not respond" (in Hebrew, the language of the participants) indicated responses that were too slow.

The auditory stimuli were four pairs of pure tones; each pair consisted of two tones of different pitch $(400+500 \mathrm{~Hz}, 600+700 \mathrm{~Hz}$, $800+900 \mathrm{~Hz}$, and $1000+1100 \mathrm{~Hz}$ ). The mask was white noise presented in each channel (ear) immediately after presentation of the pure tone. Tones were played with external loudspeakers, presented over earphones, and were well above threshold.

Task and Procedure. Each participant was assigned to one of the second-response conditions (corrections or approvals) and to one of the load conditions (irrelevant two tones, relevant single tone, or relevant two tones) according to the order of entry. Each load condition included 24 blocks of 20 trials each. The participants sat about $50 \mathrm{~cm}$ from a 14-in. monitor controlled by a desktop computer, their heads located approximately $50 \mathrm{~cm}$ from the center of the screen, in a sound-proofed room. They were asked to memorize two pure tones of elevating pitch. Pressing the Enter key initiated the tones in a consecutive order from the lower pitch to the higher pitch. The participants were given free time to memorize the tones. After memorizing the tones, the participants were asked to memorize three groups of three digits each, so that each group of digits corresponded to one of three response keys. For example, the digits 2,5 , and 8 could be mapped to the $\mathrm{V}$ key, the digits 1,6 , and 7 to the B key, and the digits 3, 4, and 9 to the N key. (These three keys are next to each other and are placed in the lower middle part of the keyboard.) The participants took as long as needed to memorize this mapping.

After memorizing, testing began. The participants in the correction condition were instructed to produce a second response immediately after the production of the initial response only if they felt that they had erred, by pressing the correct key. The participants in the approval condition were instructed to ignore their errors. However, they were instructed to respond to each target stimulus twice: the initial response, made by pressing the appropriate key with the corresponding finger, and immediately afterward an approval response, which was as follows. In the odd blocks, if the initial response was produced with the index finger on the V key, approval response was produced with the middle finger on the B key; if the initial response was produced with the middle finger on the B key, the approval response was produced with the ring finger on the $\mathrm{N}$ key; and if the initial response was produced with the ring finger on the $\mathrm{N}$ key, the approval response was produced with the index finger on the V key. In the even blocks, if the initial response was produced with the ring finger on the $\mathrm{N}$ key, the approval response was produced with the middle finger on the B key; if the initial response was produced with the middle finger on the B key, the approval response was produced with the index finger on the V key; and if the initial response was produced with the index finger on the V key, the approval response was produced with the ring finger on the $\mathrm{N}$ key. During the entire block, all three fingers were placed on each of the relevant keys. In each experimental block, a new pair of tones and a new mapping of digits to responses were introduced in order to prevent strong learning effects, making the task difficult and inducing errors. The participants were asked to produce both initial and second responses as quickly and accurately as possible. Finally, the participants were told that the two tasks (visual task and auditory task) were equally important.

An experimental trial began with the presentation of a fixation frame for $100 \mathrm{msec}$, followed by the target digit inside the frame for $100 \mathrm{msec}$. The participant was allowed $1.5 \mathrm{sec}$ to respond before receiving the Hebrew caption, equivalent to "you did not respond," for $250 \mathrm{msec}$, signaling the cancellation of the trial. If the participant responded in time, he or she was given an additional $1.5 \mathrm{sec}$ from the initial response either to correct himself or herself in the correction condition or to approve the initial response in the ap- proval condition. In the first load (irrelevant two tones) condition, $1.8 \mathrm{sec}$ after the production of the initial response, the next trial began. In the second (relevant single tone) and the third (relevant two tones) load conditions, $1.5 \mathrm{sec}$ after the production of the initial response, the participants were requested to give another response, with no time pressure. This response involved deciding whether either the high pitch or the low pitch tone had been presented, by pressing with the left hand on the 1 or 2 number key on the keyboard (in the second load condition) or deciding whether the second tone was lower or higher than the first by pressing with the left hand on one of the 1 or 2 number keys (in the third load condition). The tones stimulus-response mapping was randomly switched from trial to trial to prevent the participants from preparing the response to the interference until after $1.5 \mathrm{sec}$ from the initial response. The current mapping appeared on the screen $1.5 \mathrm{sec}$ after the production of the initial response. The next trial began $200 \mathrm{msec}$ after the production of the response to the interference.

The interference manipulation. Because it is not possible to foresee how long it will take to respond in any given trial, the computer program predicted the initial RT on the basis of the performance in the preceding block of trials. Thus, the first block was a training block with no interference, the second block was also without interference, and the mean RT for initial responses was used in the third block, which included interference. From the fourth block onward, the predicted RT was based on the preceding block. The timing of the interference was programmed so that it would appear at three time frames, between 150 and $50 \mathrm{msec}$ before the anticipated response, between $50 \mathrm{msec}$ before the anticipated response and $50 \mathrm{msec}$ after it, and between 50 and $150 \mathrm{msec}$ after the anticipated response.

The interference consisted of four tone pairs, each of which consisted of two tones of different pitch $(400+500 \mathrm{~Hz}, 600+700 \mathrm{~Hz}$, $800+900 \mathrm{~Hz}$, and $1000+1100 \mathrm{~Hz}$ ). Tone pairs were randomly assigned to any given block, so that each pair served in six blocks, but never in two successive blocks. In the irrelevant two-tones load condition, two tones out of one of the eight tone pairs were presented, one immediately after the other for $50 \mathrm{msec}$ each, one in each ear. The participants were instructed to ignore the tones. In the relevant singletone load condition, within block, only one tone was presented, and it was randomly chosen for each trial. The tone was presented for $100 \mathrm{msec}$ at the end of each trial, with no time pressure; the participants were requested to decide whether the tone was of the high or the low pitch. The relevant two-tones load condition was identical to the irrelevant two-tones load condition, except that at the end of each trial, the participants were requested to decide, with no time pressure, whether the second tone was higher or lower than the first. In all the load conditions, immediately after presentation of each tone, a white noise mask was presented. In the irrelevant and relevant two-tones load conditions, the mask was presented for $50 \mathrm{msec}$. In the relevant single-tone load condition, the mask was presented for $100 \mathrm{msec}$. In the relevant single-tone load condition, the tones within each block were randomly assigned between the ears. Each of the ears received half of the tones. In the two-tones load conditions, in each block, the high-pitch tone and the low-pitch tone were randomly assigned between the ears. However, in each trial, a different tone was presented to each ear.

\section{Results}

Analytic method. In the statistical analysis, interfering stimuli appearing between $200 \mathrm{msec}$ before the actual initial response and $50 \mathrm{msec}$ before the actual initial response were sorted as before. Interfering stimuli appearing between $50 \mathrm{msec}$ before the actual initial response and $100 \mathrm{msec}$ after it were sorted as during, and interfering stimuli appearing between $100 \mathrm{msec}$ after the actual initial response and $250 \mathrm{msec}$ after it were sorted as after. 
We conducted a series of three-way analyses of variance (ANOVAs) with interference load (irrelevant, relevant single tone, or relevant two tones) and response type (corrections or approvals) as between-subjects variables and actual interference timing (before, during, or after) as a within-subjects variable. The dependent measures were RT1 (measured from the appearance of the target digit to the execution of the initial response), the interresponse time (IRT; measured from the initial response to the execution of the second response), the proportion of correct recall in the memory task (the responses to the interference stimuli), and the proportion of errors. In all the analyses, we adopted an $\alpha=.05$. Any RT values that fell outside of the range of 200-1,300 msec (which appeared as outliers by a visual inspection of the RT histogram) were considered likely to be spurious and were eliminated from the distribution $(2.8 \%$ of all the responses). We also excluded from the analysis trials in which the second response was wrong (corrections, 3.4\% of correction responses; approvals, $7.9 \%$ of approval responses), since there were not enough responses of that kind to analyze.

Error rates. The error rates were $22 \%$ and $24 \%$ in corrections and approvals, respectively. In corrections, $64 \%$ of the erroneous responses were corrected. Since most of the errors in corrections were corrected, it seems reasonable to presume that in approvals, most of the errors were detected, although in the present study there is no direct way of measuring error detection in this group.

IRT analysis. We divided the approvals response type into two groups, differentiated by the nature of the initial response. One group, termed wrong approvals, included responses in which the initial response to the target stimuli was wrong. The other group, termed correct approvals, included responses in which the initial response to the target stimuli was correct. As can be seen in Table 1, a $t$ test between these groups revealed longer IRTs for wrong approvals $(M=679 \mathrm{msec})$ than for correct approvals $[M=645 \mathrm{msec} ; t(29)=4.85]$. We interpreted these results as indicating the existence of an error process in wrong approvals that occurred despite the instruction given to the participants to ignore their errors in the approvals condition. These results led us to conduct a separate ANOVA on each of the approval response groups.

Correct approvals. There was a significant three-way interaction between response type, load, and actual interference timing $\left[F(2,120)=7.86, M S_{\mathrm{e}}=1,345.16\right]$. As we predicted (Figure 1), when the interference was relevant, only corrections were affected by the presence of interference with the before interference timing. Both response types were affected by the relevant interference for the during interference timing but were not affected for the after interference timing. The irrelevant interference had no effect for both response types.

A comparison between the relevant load conditions revealed longer IRTs at two tones than at a single tone $\left[F(1,38)=6.86, M S_{\mathrm{e}}=1,400.43\right]$. A comparison within the correction condition for the relevant single tone re-
Table 1

Experiment 1: Mean First Response Times (RT1s, in Milliseconds) and Mean Interresponse Times (IRTs, in Milliseconds) According to Actual Interference Timing for Load Conditions 1-3

\begin{tabular}{|c|c|c|c|}
\hline \multirow[b]{2}{*}{ Timing } & \multicolumn{3}{|c|}{ Load } \\
\hline & Irrelevant & Single Tone & Two Tones \\
\hline \multicolumn{4}{|c|}{ Corrections Response Group } \\
\hline \multicolumn{4}{|l|}{ Before } \\
\hline RT1 & 796 & 783 & 774 \\
\hline IRT & 639 & 694 & 773 \\
\hline \multicolumn{4}{|l|}{ During } \\
\hline RT1 & 809 & 803 & 789 \\
\hline IRT & 622 & 707 & 756 \\
\hline \multicolumn{4}{|l|}{ After } \\
\hline RT1 & 776 & 800 & 801 \\
\hline IRT & 627 & 622 & 633 \\
\hline \multicolumn{4}{|c|}{ Wrong Approvals Response Group } \\
\hline \multicolumn{4}{|c|}{ 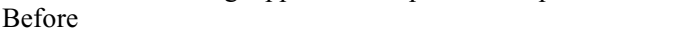 } \\
\hline RT1 & 813 & 794 & 783 \\
\hline IRT & 683 & 629 & 606 \\
\hline \multicolumn{4}{|l|}{ During } \\
\hline RT1 & 817 & 758 & 799 \\
\hline IRT & 675 & 703 & 785 \\
\hline \multicolumn{4}{|l|}{ After } \\
\hline RT1 & 783 & 777 & 807 \\
\hline IRT & 682 & 671 & 673 \\
\hline \multicolumn{4}{|c|}{ Correct Approvals Response Group } \\
\hline \multicolumn{4}{|c|}{ 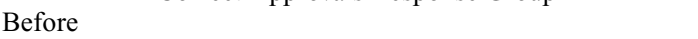 } \\
\hline RT1 & 813 & 789 & 781 \\
\hline IRT & 629 & 612 & 607 \\
\hline \multicolumn{4}{|l|}{ During } \\
\hline RT1 & 811 & 774 & 806 \\
\hline IRT & 619 & 711 & 764 \\
\hline \multicolumn{4}{|l|}{ After } \\
\hline RT1 & 772 & 789 & 807 \\
\hline IRT & 623 & 629 & 613 \\
\hline
\end{tabular}

vealed no difference between the before and during interference timings $\left[F(1,9)=2.16, M S_{\mathrm{e}}=16,420.40\right]$. Hence, both were pulled together and compared with the after interference timing, revealing a significant difference in IRT $\left[F(1,9)=7.26, M S_{\mathrm{e}}=3,348.34\right]$. Comparisons within correct approvals for both relevant single tone and relevant two tones revealed no significant difference between the before and the after interference timings. Hence, both were pulled together and compared with the during interference timing, revealing a significant difference in IRT $\left[F(1,9)=8.34, M S_{\mathrm{e}}=5,223.12\right]$. Comparisons within each response type for the irrelevant load condition revealed no significant differences among actual interference timings.

Wrong approvals. The three-way interaction was significant $\left[F(2,120)=8.87, M S_{\mathrm{e}}=1,567.00\right]$. As can be seen in Figure 1, when the interference was relevant, both corrections and approvals were affected by the presence of interference with the before interference timing. However, whereas in corrections IRT was elongated, in approvals IRT was shortened. Both response types were affected by the relevant interference with the during interference timing but were not affected with the after in- 

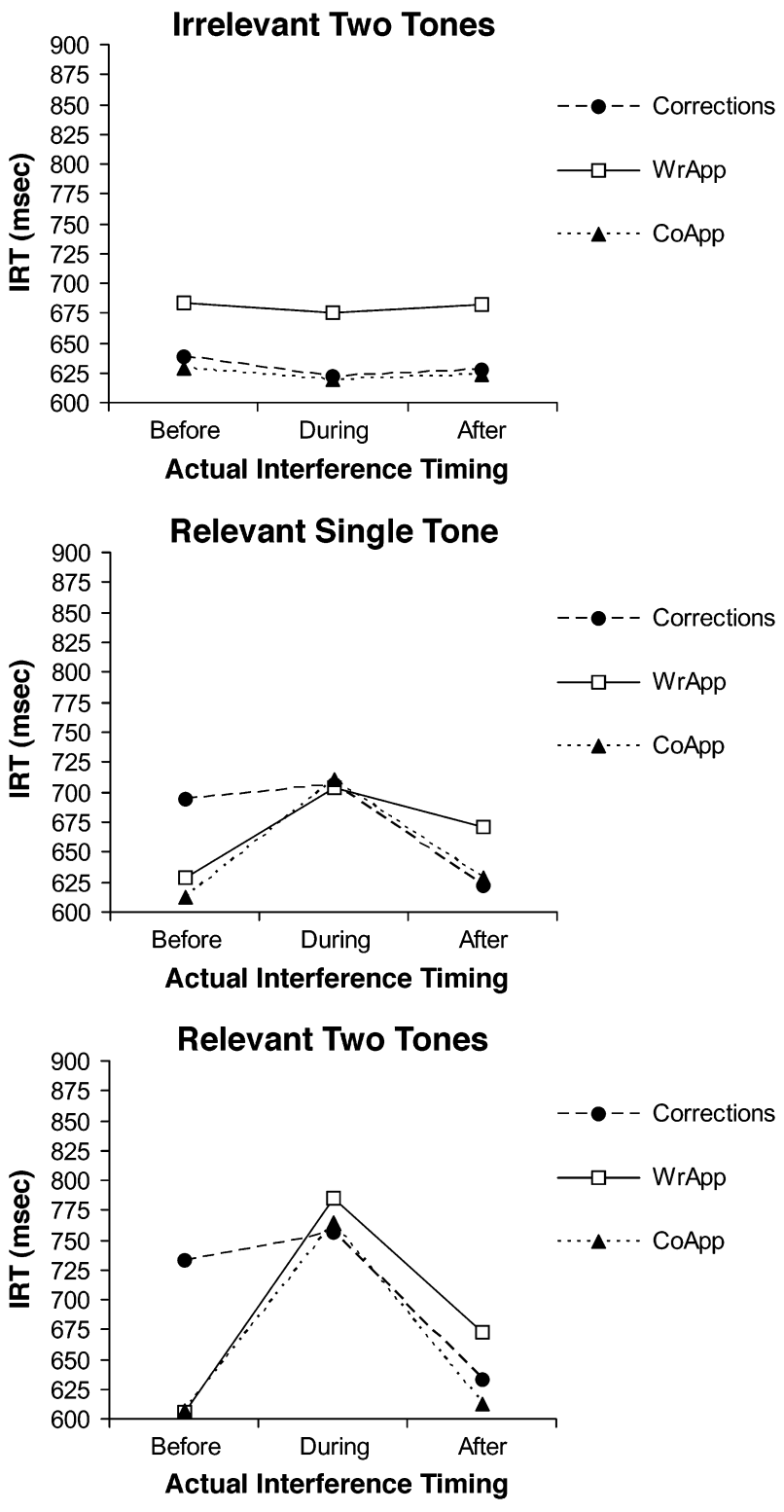

Figure 1. Experiment 1: interresponse time (IRT) as a function of response group and actual interference timing for Load Conditions 1-3. WrApp, wrong approvals; CoApp, correct approvals.

terference timing. The irrelevant interference had no effect for both response types. Comparisons within wrong approvals for both relevant single tone and relevant two tones revealed significantly shorter IRTs for the before as opposed to the after, interference timing [relevant single tone, $F(1,9)=7.67, M S_{\mathrm{e}}=3,430.40$; relevant two tones, $\left.F(1,9)=6.89, M S_{\mathrm{e}}=12,934.78\right]$ and for the after, as opposed to the during, interference timing [relevant single tone, $F(1,9)=9.76, M S_{\mathrm{e}}=6,780.00$; relevant two tones, $\left.F(1,9)=9.94, M S_{\mathrm{e}}=14,965.14\right]$. A comparison within the before interference timing between the relevant load conditions revealed no significant difference in IRT. However, both relevant load conditions revealed shorter IRTs for the before interference timing, as opposed to the irrelevant load condition [relevant single tone, $F(1,18)=12.76, M S_{\mathrm{e}}=6,785.07$; relevant two tones, $\left.F(1,18)=13.62, M S_{\mathrm{e}}=8,934.18\right]$.

RT1 analysis. Rabbitt (1966b) claimed that erroneous responses are slower than correct responses if they reflect a memory failure and faster than correct responses if they result from premature responses. It is likely that different kinds of errors are followed by somewhat different error processes. However, a $t$ test between erroneous responses and correct responses revealed no significant difference for both approvals [correct responses, $M=793 \mathrm{msec}$; errors, $M=792 \mathrm{msec} ; t(29)=1.05]$ and corrections [correct responses, $M=816 \mathrm{msec}$; errors, $M=794 \mathrm{msec} ; t(29)=1.06]$. Also as can be seen in Figure 1, no significant effects were found in the ANOVA ( $p>.1$ for all comparisons).

Tone memory performance. The following section will show that, as would be expected from dual-task experiments in which one stimulus is to be responded to immediately and the other is to be recalled later, whenever the speeded task was hindered, recall performance was barely affected. The overall proportion of correct recalls was .82 in the relevant two-tones load condition and .95 in the relevant single-tone load condition. The threeway interaction between response type, load (relevant two tones or relevant single tone), and actual interference timing was not significant $\left[F(2,120)=2.03, M S_{\mathrm{e}}=\right.$ $7,543.0]$. The main effects of response type $[F(2,120)=$ $\left.2.96, M S_{\mathrm{e}}=5,034.324\right]$ and actual interference timing $\left[F(2,120)=1.03, M S_{\mathrm{e}}=4,538.45\right]$ were not significant. The main effect of load was significant $[F(2,120)=8.77$, $\left.M S_{\mathrm{e}}=6,666.873\right]$, revealing lower recall performance for relevant two tones than for relevant single tone.

Error proportions. No significant effects were found in the ANOVA ( $p>.1$ in all comparisons). We also conducted a two-way ANOVA on proportion of correction responses with interference load and actual interference timing as factors. No significant effects were found in the analysis ( $p>.1$ in all comparisons).

\section{EXPERIMENT 2}

\section{Method}

Experiment 2 was identical to Experiment 1, except as will be noted.

Participants. Sixty participants took part in the experiment.

Stimuli. An arrow subtending $0.5^{\circ}$ of visual angle appeared in the middle of the computer screen and indicated whether the approval response was to be made using the one-to-the-right rule or the one-to-the-left rule.

Procedure. In the approval group, the participants were told that a second response was to be made only if an arrow appeared immediately after the production of the initial response. The arrow appeared randomly, for $50 \mathrm{msec}$, immediately after the production of the initial response on about one seventh of the trials in each block, which was the proportion of correction responses out of all the responses in Experiment 1). The arrow could point either to the right (indicating the following initial-to-second-response mapping: 
index-middle, middle-ring, ring-index) or to the left (indicating the following initial-to-second-response mapping: ring-middle, middle-index, index-ring).

\section{Results}

Analytic method. We used the same procedure as in Experiment 1. Of all the responses, $2.8 \%$ were considered as outliers and were eliminated from the analysis. We also excluded from the analysis trials on which the second response was wrong (corrections, $3.1 \%$ of correction responses; approvals, $9.9 \%$ of approval responses), since there were not enough responses of that kind to analyze.

Error rates. The error rates were $27 \%$ and $29 \%$ in corrections and approvals, respectively. In corrections, $71 \%$ of the erroneous responses were corrected.

IRT analysis. As can be seen in Table 2, a $t$ test between correct approvals and wrong approvals revealed longer IRTs for wrong approvals $(M=736 \mathrm{msec})$ than for correct approvals $(M=701 \mathrm{msec} ; t(29)=3.86]$.

Correct approvals. There was a significant three-way interaction between response type, load, and actual interference timing $\left[F(2,120)=8.83, M S_{\mathrm{e}}=5,467.76\right]$. As can be seen in Figure 2, when the interference was relevant, only corrections were affected by the presence of interference with the before interference timing. Both response types were affected by the relevant interference for the during interference timing but were not affected for the after interference timing. The irrelevant interference had no effect on both response types.

A comparison between the relevant load conditions revealed longer IRTs for two tones than for single tone $\left[F(1,38)=7.96, M S_{\mathrm{e}}=5,430.72\right]$. A comparison within the correction condition for the relevant single tone revealed no difference between the before and the during interference timings $\left[F(1,9)=1.99, M S_{\mathrm{e}}=6,543.92\right]$. Hence, both were pulled together and compared with the after interference timing, revealing a significant difference in IRT $\left[F(1,9)=7.01, M S_{\mathrm{e}}=5,328.20\right]$. Comparisons within correct approvals for both relevant single tone and relevant two tones revealed no significant difference between the before and the after interference timings. Hence, both were pulled together and compared with the during interference timing, revealing a significant difference in IRT $\left[F(1,9)=10.54, M S_{\mathrm{e}}=1,234.32\right]$. Comparisons within each response type for the irrelevant load condition revealed no significant differences among actual interference timings.

Wrong approvals. The three-way interaction was significant $\left[F(2,120)=8.01, M S_{\mathrm{e}}=2,324.91\right]$. As can be seen in Figure 2, when the interference was relevant, both corrections and approvals were affected by the presence of interference for the before interference timing. However, whereas in corrections IRT was elongated, in approvals IRT was shortened. Both response types were affected by the relevant interference for the during interference timing but were not affected for the after interference timing. The irrelevant interference had no effect on both response types. Comparisons within wrong ap-
Table 2

Experiment 2: Mean First Response Times (RT1s, in Milliseconds) and Mean Interresponse Times (IRTs, in Milliseconds) According to Actual Interference Timing for Load Conditions 1-3

\begin{tabular}{|c|c|c|c|}
\hline \multirow[b]{2}{*}{ Timing } & \multicolumn{3}{|c|}{ Load } \\
\hline & Irrelevant & Single Tone & Two Tones \\
\hline \multicolumn{4}{|c|}{ Corrections Response Group } \\
\hline \multicolumn{4}{|l|}{ Before } \\
\hline RT1 & 798 & 768 & 793 \\
\hline IRT & 604 & 671 & 703 \\
\hline \multicolumn{4}{|l|}{ During } \\
\hline RT1 & 811 & 779 & 790 \\
\hline IRT & 617 & 698 & 727 \\
\hline \multicolumn{4}{|l|}{ After } \\
\hline RT1 & 774 & 786 & 814 \\
\hline IRT & 612 & 626 & 639 \\
\hline \multicolumn{4}{|c|}{ Wrong Approvals Response Group } \\
\hline \multicolumn{4}{|l|}{ Before } \\
\hline RT1 & 816 & 797 & 789 \\
\hline IRT & 717 & 664 & 674 \\
\hline \multicolumn{4}{|l|}{ During } \\
\hline RT1 & 824 & 780 & 807 \\
\hline IRT & 734 & 789 & 861 \\
\hline \multicolumn{4}{|l|}{ After } \\
\hline RT1 & 781 & 761 & 801 \\
\hline IRT & 743 & 728 & 713 \\
\hline \multicolumn{4}{|c|}{ Correct Approvals Response Group } \\
\hline \multicolumn{4}{|l|}{ Before } \\
\hline RT1 & 823 & 815 & 773 \\
\hline IRT & 671 & 689 & 696 \\
\hline \multicolumn{4}{|l|}{ During } \\
\hline RT1 & 823 & 767 & 819 \\
\hline IRT & 643 & 760 & 839 \\
\hline \multicolumn{4}{|l|}{ After } \\
\hline RT1 & 778 & 775 & 820 \\
\hline IRT & 667 & 659 & 681 \\
\hline
\end{tabular}

provals for both relevant single tone and relevant two tones revealed significantly shorter IRTs for the before, as opposed to the after, interference timing [relevant single tone, $F(1,9)=5.97, M S_{\mathrm{e}}=3,421.84$; relevant two tones, $\left.F(1,9)=6.00, M S_{\mathrm{e}}=2,314.63\right]$ and for the after, as opposed to the during, interference timing [relevant single tone, $F(1,9)=9.76, M S_{\mathrm{e}}=3,456.00$; relevant two tones, $\left.F(1,9)=9.91, M S_{\mathrm{e}}=1,000.76\right]$. A comparison within the before interference timing between the relevant load conditions revealed no significant difference in IRT. However, both relevant load conditions revealed shorter IRTs for the before interference timing, as opposed to the irrelevant load condition [relevant single tone, $F(1,18)=13.43, M S_{\mathrm{e}}=7,654.87$; relevant two tones, $\left.F(1,18)=15.12, M S_{\mathrm{e}}=9,876.65\right]$.

RT1 analysis. A $t$ test between erroneous responses and correct responses revealed no significant difference for both approvals [correct responses, $M=799 \mathrm{msec}$; errors, $\left.M=795 \mathrm{msec} ; t(29)=1.01, M S_{\mathrm{e}}=1,987.03\right]$ and corrections [correct responses, $M=803 \mathrm{msec}$; errors, $M=784 \mathrm{msec} ; t(29)=1.03]$. Also, as can be seen in Table 2, no significant effects were found in the ANOVA ( $p>.1$ for all comparisons). 

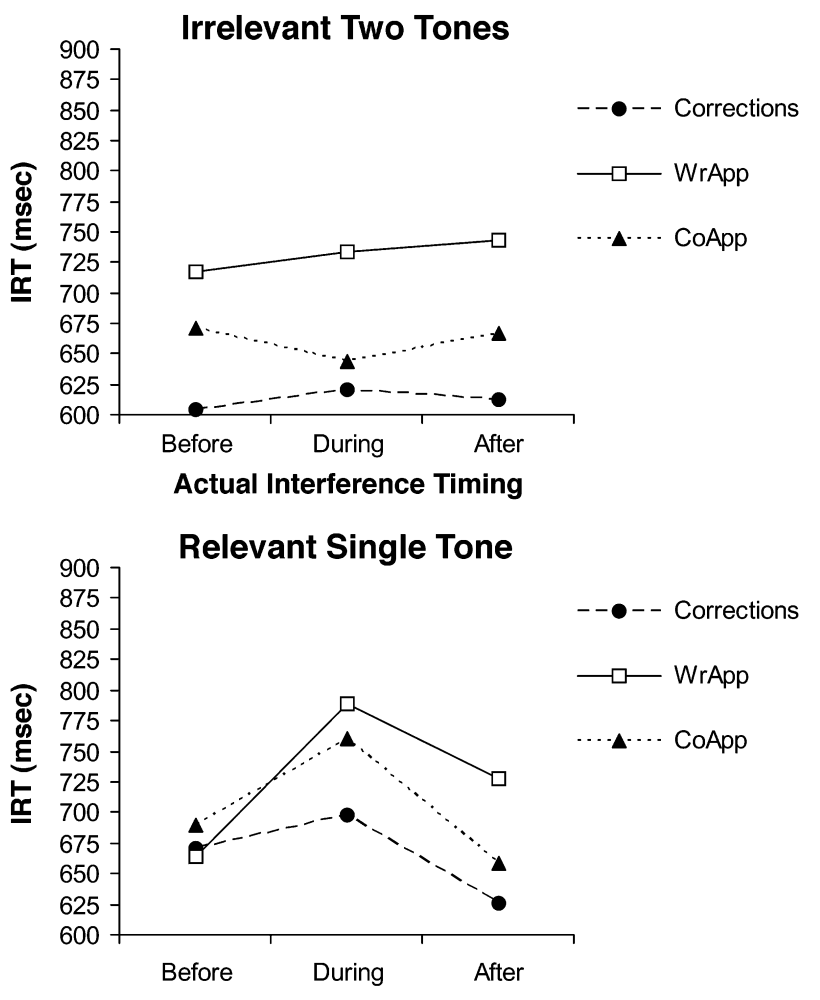

Actual Interference Timing

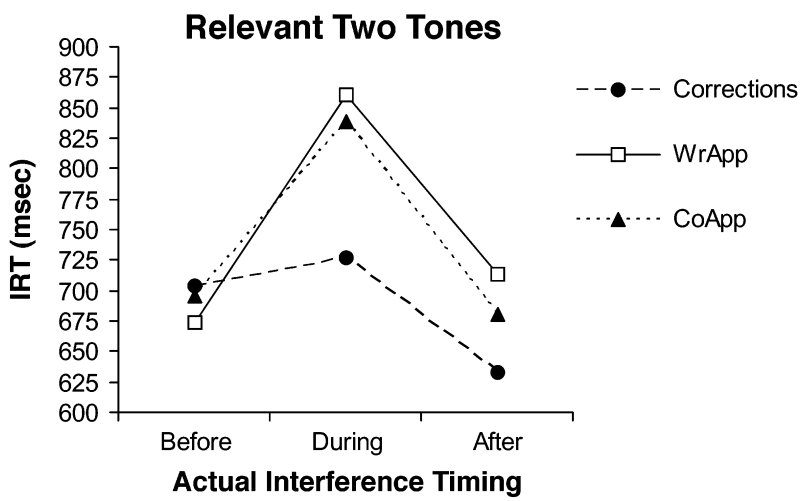

Figure 2. Experiment 2: interresponse time (IRT) as a function of response groups and actual interference timing for Load Conditions 1-3. WrApp, wrong approvals; CoApp, correct approvals.

Tone memory performance. The overall proportion of correct recalls was .83 in the relevant two-tones load condition and .89 in the relevant single-tone load condition. The three-way interaction between response type, load (relevant two tones or relevant single tone), and actual interference timing was not significant $[F(2,120)=$ 2.21, $\left.M S_{\mathrm{e}}=6,754.32\right]$. The main effects of response type $\left[F(2,120)=1.40, M S_{\mathrm{e}}=3,214.76\right]$ and actual interference timing $\left[F(2,120)=2.03, M S_{\mathrm{e}}=7,932.41\right]$ were not significant. The main effect of load was significant $\left[F(2,120)=13.88, M S_{\mathrm{e}}=3,752.69\right]$, revealing lower recall performance for relevant two tones than for relevant single tone.
Error proportions. No significant effects were found in the ANOVA ( $p>.1$ in all the comparisons). We also conducted a two-way ANOVA on proportion of correction responses with interference load and actual interference timing as factors. No significant effects were found in the analysis ( $p>.1$ in all the comparisons).

\section{GENERAL DISCUSSION}

The present study dealt with capacity limitations in the error-processing system. In two experiments, we compared the effect of interference on correction responses following erroneous responses with its effect on approval responses following either erroneous responses or correct responses. The interfering stimuli appeared slightly before, roughly during, or slightly after the production of the initial response. Differential interference effects for corrections and wrong approvals, as compared with correct approvals, were found only when the interference was relevant - that is, had to be recalled later-and when it was presented before the initial response. The effects of the interference on corrections and wrong approvals with the before interference timing were opposite. Whereas in corrections IRT was elevated, in wrong approvals IRT was shortened.

We assume that the order of events in the before interference timing was as follows. Since the three response groups did not differ in RT1, the consolidation in STM of the interference presented with the before interference timing probably coincided with the same stage in the initial response programming for all three response groups. At this stage, an error process was ongoing in corrections. The interfering stimulus coincided with the error process and postponed it until after the interference had been consolidated in STM, resulting in a postponement of the correction response.

In correct approvals for before, at the stage in the initial response programming at which the interference was consolidated in STM, no central process other than STM consolidation was ongoing. For that reason, the interference had no effect on IRT in correct approvals. Note that it is reasonable to assume that the approval response was not selected until after the initial response was executed, to avoid a response conflict (i.e., simultaneous activation of incompatible response tendencies) between the initial response and the approval response. Because the initial response and the approval response were to be made by adjacent fingers, the risk of a response conflict was indeed high.

In wrong approvals, the interference coincided with the error process. The error process was postponed until the stage at which the approval response was to be selected. Again, the error process was postponed until after the selection of the approval response. The postponement of the error process resulted in an IRT for wrong approvals with the before interference timing that was equal to the IRT for correct approvals. Note that beyond interference timings, we found IRTs for wrong approvals 
to be longer than IRTs for correct approvals. This might mean that when the error process had reached a certain point without being interfered with-perhaps the point at which selection of the correction response occurredthe error process could no longer be delayed. Rather, the selection of the correction response encountered the selection of the approval response and interfered with it.

In contrast to interference presented before the initial response, interference presented concurrently with it impaired responses, both in the approval groups and the correction response group similarly. We presume that in all three response groups, the selection of the second response (correction response or approval response) coincided with the consolidation of the interference in STM with the during interference timing.

Hence, on the basis of our findings, we argue that the error process is generated before a response is given and that it is automatic, in the sense of being activated despite the participant's conscious will to suppress it (in the approvals response type), and yet it is a central process in terms of being subjected to capacity limitations in the presence of other central processes (Jolicœur \& Dell'Acqua, 1998).

\section{REFERENCES}

Angel, R. W., Garland, H., \& Fischler, M. (1971). Tracking errors amended without visual feedback. Journal of Experimental Psychology, 89, 422-424.

BernStein, P. S., Scheffers, M. K., \& Coles, M. G. H. (1995). "Where did I go wrong?" A psychophysiological analysis of error detection. Journal of Experimental Psychology: Human Perception \& Performance, 21, 1312-1322.

CARRIER, L. M., \& PASHLER, H. (1995). Attentional limits in memory retrieval. Journal of Experimental Psychology: Learning, Memory, \& Cognition, 21, 1339-1348.

CARTER, C. S., Botvinick, M. M., \& Cohen, J. D. (1999). The contribution of the anterior cingulate cortex to executive processes in cognition. Reviews in the Neurosciences, 10, 49-57.

Carter, C. S., Braver, T. S., Barch, D. M., Botvinick, M. M., Noll, D., \& Cohen, J. D. (1998). Anterior cingulate cortex, error detection, and the online monitoring of performance. Science, 280, 747-749.

Carter, C. S., Macdonald, A. M., Botvinick, M., Ross, L. L., StenGer, V. A., Noll, D., \& Cohen, J. D. (2000). Parsing executive processes: Strategic vs. evaluative functions of the anterior cingulate cortex. Proceedings of the National Academy of Sciences, 97, 1944-1948.

Cooke, J. D., \& DigGles, V. A. (1984). Rapid error correction during human arm movements: Evidence for central monitoring. Journal of Motor Behavior, 16, 348-363.

Falkenstein, M., Hohnsbein, J., Hoormann, J., \& Blanke, L. (1990). Effects of errors in choice reaction tasks on the ERP under focused and divided attention. In C. H. M. Brunia, A.W. K. Gaillard, \& A. Kok (Eds.), Psychophysiological brain research (pp. 192-195). Tilburg, The Netherlands: Tilburg University Press.

Falkenstein, M., Hohnsbein, J., Hoormann, J., \& Blanke,L. (1991). Effects of crossmodal divided attention on late ERP components: II. Error processing in choice reaction tasks. Electroencephalography \& Clinical Neurophysiology, 78, 447-455.

FaLKenstein, M., HoORMANN, J., \& HohnsBein, J. (1999). ERP com- ponents in Go-NoGo tasks and their relation to inhibition. Acta Psychologica, 101, 267-291.

GeHRING, W. J., \& FENCSIK, D. E. (1999, April). Slamming on the brakes: An electrophysiological study of error response inhibition. Paper presented at the annual meeting of the Cognitive Neuroscience Society, Washington, DC.

Gehring, W. J., Goss, B., Coles, M. G., \& Meyer, D. E. (1993). A neural system for error detection and compensation. Psychological Science, 4, 385-390.

HIGGINS, J., \& ANGEL, R. W. (1970). Correction of tracking errors without sensory feedback. Journal of Experimental Psychology, 84, 412416.

Hochman, E. Y., \& Eviatar, Z. (2004). Does each hemisphere monitor the ongoing process in the contralateral one? Brain \& Cognition, 55, 314-321.

JoLICEUR, P. (1998). Modulation of the attentional blink by on-line response selection: Evidence from speeded and unspeeded Task deci- $_{1}$ sions. Memory \& Cognition, 26, 1014-1032.

JolicceuR, P. (1999a). Dual-task interference and visual encoding. Journal of Experimental Psychology: Human Perception \& Performance, 25, 596-616.

JoLICEUR, P. (1999b). Restricted attentional capacity between sensory modalities. Psychonomic Bulletin \& Review, 6, 87-92.

JOLICEUR, P., \& DELL'ACQUA, R. (1998). The demonstration of shortterm consolidation. Cognitive Psychology, 36, 138-202.

McCANn, R. S., \& JohNSTON, J. C. (1992). Locus of the single-channel bottleneck in dual-task interference. Journal of Experimental Psychology: Human Perception \& Performance, 18, 471-484.

NAVON, D., \& MiLLER, J. (2002). Queuing or sharing? A critical evaluation of the single-bottleneck notion. Cognitive Psychology, 44, 193-251.

Nieuwenhuis, S., RidDerinkhof, K. R., Blom, J., BAND, G. P. H., \& KoK, A. (2001). Error-related brain potentials are differentially related to awareness of response errors: Evidence from an antisaccade task. Psychophysiology, 38, 752-760.

Pashler, H. (1994). Dual-task interference in simple tasks: Data and theory. Psychological Bulletin, 116, 220-244.

Pashler, H., \& Johnston, J. C. (1998). Attentional limitations in dualtask performance. In H. Pashler (Ed.), Attention (pp. 89-155). Hove, U.K.: Psychology Press.

Rabiitt, P. M. A. (1966a). Error-correction time without external signals. Nature, 212, 438.

RabiITT, P. M. A. (1966 b). Errors and error-correction in choice response tasks. Journal of Experimental Psychology, 71, 264-272.

RabBiTt, P. M. A. (1967). Three kinds of error-signaling responses in a serial choice task. Quarterly Journal of Experimental Psychology, 22, 179-188.

Rabiitt, P. [M. A.] (2002). Consciousness is slower than you think. Quarterly Journal of Experimental Psychology, 55A, 1081-1092.

Ruthruff, E., Miller, J., \& Lachman, T. (1995). Does mental rotation require central mechanisms? Journal of Experimental Psychology: Human Perception \& Performance, 21, 552-570.

ViDAL, F., HasbroucQ, T., GrapPeron, J., \& BonNeT, M. (2000). Is the "error negativity" specific to errors? Biological Psychology, 51, 109128.

VINCE, M. A. (1948). The intermittency of control movements and the psychological refractory period. British Journal of Psychology, 38, 149-157.

Welford, A. T. (1952). The "psychological refractory period" and the timing of high-speed performance: A review and a theory. British Journal of Psychology, 43, 2-19.

(Manuscript received January 12, 2004; revision accepted for publication August 3, 2004.) 